\title{
Topographical Analysis of Frontal Lobe Executive Functions in Patients Following a Stroke
}

\author{
Roberta Márcia Torres, Kristiana Cerqueira Mousinho, Liércio Pinheiro, \\ Nathália Costa Toledo Pacheco Piatti, Taise Almeida Cavalcante, Aline da Silva Amorim, \\ Ana Karolina Barros de Jesus, Maria Wylianna Oliveira dos Santos, \\ Euclides Maurício Trindade Filho
}

University Center CESMAC, Maceió, Brazil

Email: emtfilho@gmail.com

Received 16 March 2016; accepted 9 May 2016; published 12 May 2016

Copyright (C) 2016 by authors and Scientific Research Publishing Inc. This work is licensed under the Creative Commons Attribution International License (CC BY). http://creativecommons.org/licenses/by/4.0/

(c) ()

\begin{abstract}
Objective: This study aimed to carry out a topographical analysis of frontal lobe executive function components in post-stroke patients. Methods: A descriptive, cross-sectional study. The assessment using the WCST (Wisconsin Card Sorting Test) included sixteen patients with a clinical diagnosis of CVA and frontal lobe impairment. Results from the two groups were compared (patients with right frontal lobe impairment and patients with left frontal lobe impairment). Statistical analysis was performed using the program "Statistical Package for Social Sciences" (SPSS) Version 20.0. For comparison between groups was used Mann-Whitney test and considered the alpha level of 0.05 on the statistically significant results. Results: There was no statistically significant difference between the groups, thus showing that executive functions are symmetrically distributed across the frontal lobes. Conclusion: Executive functions are symmetrically organized across the two frontal lobes, since the comparison between the groups did not demonstrate a statistically significant difference for any of the variables of WSCT.
\end{abstract}

\section{Keywords}

Executive Function, Stroke, Frontal Lobe, Neuropsychology

\section{Introduction}

The term executive function refers to cognitive abilities involved in planning, starting, carrying out, and moni-

How to cite this paper: Torres, R.M., Mousinho, K.C., Pinheiro, L., Piatti, N.C.T.P., Cavalcante, T.A., da Silva Amorim, A., de Jesus, A.K.B., dos Santos, M.W.O. and Filho, E.M.T. (2016) Topographical Analysis of Frontal Lobe Executive Functions in Patients Following a Stroke. World Journal of Neuroscience, 6, 143-150. http://dx.doi.org/10.4236/wjns.2016.62018 
toring complex behaviors that require attention, concentration, selectiveness of stimuli, abstract thinking, planning, cognitive flexibility, self-control, and memory [1]. In addition, they enable us to transform thoughts into actions, to initiate or inhibit attention, to interact with other people in discussions or talks, and to plan a specific approach to each objective.

The symptoms associated with executive dysfunction are strongly related to Cerebrovascular Accidents (CVA) and have been calling the attention of researchers, particularly with regard to the drawing up of steps to assess such dysfunction after a cerebrovascular injury [2].

The term CVA is defined by the World Health Organization (WHO) as "focal or global neurological impairment of sudden onset, lasting for more than 24 hours (or leading to death before then), and of presumed vascular origin" [3]. Post-stroke sequelae may be permanent or transient, and are the result of either an ischemic (CVAi) or hemorrhagic (CVAh) stroke [4] that led to the reduction of blood flow to areas of the brain.

It is common for individuals who have suffered a CVA to experience a loss of cognitive function and intellectual skills [5]. These cognitive deficits may hamper motor rehabilitation and sensorimotor learning, making quick cognitive processing difficult and thus keeping one from doing day-to-day activities [6]. By looking at the blood distribution of the arteries affected by a CVA, as well as by analyzing the scope of the brain damage, one can attest and assess the resulting neuropsychological alterations. An early cognitive assessment in the acute phase after a CVA helps to determine the measures to be taken, thus bringing immeasurable benefits to the patient's rehabilitation, functional recovery, and quality of life [7].

There is currently great interest in the left hemisphere (LH) versus right hemisphere (RH) dichotomy. According to Brookshire, cerebral dominance is based on the notion that the LH is dominant and is responsible for processing language and playing a major role in voluntary movement. On the other hand, the RH is considered to be the lesser and more passive half [8] [9].

Considering the hemispheric specialization of cognitive functions, the LH is associated with linguistic skills, analytical reasoning, verbal memory, and the production and understanding of language; the RH is associated with attention, perception and visual/spatial memory, right-left awareness, social and emotional intelligence, recognition of facial expressions, and musical ability [10].

Executive function deficits have caused major functional, social, and occupational impairment to patients, making it difficult their social adaptation, functionality, and emotional control [11]. Symptoms related to dysexecutive, cognitive, and behavior disorders are seen in individuals with prefrontal circuit lesions, with distinct degrees of impairment [11] [12].

Thus, the study herein aims to analyze the topography of executive function components in patients who suffered a CVA that affected their frontal lobe.

\section{Methods}

This study was approved by the Research Ethics Committee (CEP) CESMAC University Center with the protocol number of 630.849 in 2014. This was a study of descriptive and cross-sectional, conducted in a hospital in the city of Maceio, Brazil. For the sample, they were elected 152 patients with a clinical diagnosis of stroke confirmed by computed tomography scan (CT). They included patients of both genders, aged over 18 and who have involvement of the frontal lobe by stroke. They excluded those diagnosed with psychiatric disorders, language comprehension deficiency, primary auditory or visual impairment, alcohol abuse history and/or illicit drugs (134). After application of the inclusion criteria, were selected 18 patients, and 02 of these died, leaving then 16 patients who were included in the final sample of this research. All participants gave their consent by signing the Informed Consent Form.

The patients were later divided into two groups. One group with patients who had had right frontal lobe damage (RF) and the other with those who had suffered left frontal lobe injury (LF).

A neuropsychological test was then administered by a skilled professional (psychologist), preferably in the morning, at the bedside of the patient, in the ward, always with the consent of the participants. The Wisconsin Card Sorting Test (WCST) was used to evaluate the executive functions of the brain. It assesses abstract reasoning and the thought flexibility needed to generate strategies for problem solving, in response to changing stimulus conditions [13]. A highly sensitive test, the WCST is one of the most widely used neuropsychological tests of frontal lobe dysfunctions [14]. 
The test WCST consists of four stimulus cards and 128 letters of response (02 decks of 64 cards). The stimulus letters are composed of 04 letters (one with a red triangle, one with two green stars, one with three yellow crosses and another with four blue circles). These letters reflect only three stimulus parameters to be given to the individual: color, shape and number. The response letters are contained in two decks of 64 cards that also exhibit figures in various ways (crosses, circles, triangles or stars), colors (red, blue, yellow or green) and picture numbers (one, two, three, or four figures). Each card response can be combined with a letter stimulus to a stimulus parameter, or a combination of the three parameters of stimulation. In the test application the stimulus cards are placed in front of the individual, from left to right: a letter with a red triangle, the other with two green stars, most with three yellow crosses and the last four blue circles. After this procedure, the examiner will explain to the patient that cannot tell you what to do only he does association of each card in the deck with one of the four key cards. Then it will be delivered to the individual a deck of 64 cards and is asked to do even the association of each row of the playing card with any of the four stimulus cards with which he thinks suits. It will be verbalized only if each answer is right or wrong, and under no circumstances the correct principle of classification will be revealed. After 10 hits the principle of classification will be modified to form and after 10 more hits will be modified to number, later returning to color and repeating the sequence, without notice to the individual. The test follows until the individual has successfully completed six categories or until the cards response of cards have been fully used, whichever comes first. Subsequently, the data collected relating to the responses of individuals are included in the standard normative tables of test according to age and level of education.

Statistical analysis was performed using the program "Statistical Package for Social Sciences" (SPSS) version 20.0. For comparison between groups was used Mann-Whitney test and considered the alpha level of 0.05 on the statistically significant results. Data from this study were organized descriptively in tables and graphs. For scalar variables, the analysis was done by observing the minimum and maximum values, and from obtaining means and standard deviations. For categorical variables, we calculated the absolute frequencies and percentages.

\section{Results}

The sample consisted of 16 patients who had had a cerebrovascular accident (CVA). The mean age for patients with right frontal lesion was 56.0 years and for those with left frontal lesion 54.3 years. On average, the former group had suffered the CVA 09 days before, whereas for the latter that number was 07 days (Table 1).

Table 2 shows the analysis of the socio-demographic characteristics of the sample.

Clinical data of patients in both groups can be seen in Table 3 .

Table 4 brings the scores achieved by the individuals in the two groups in the Wisconsin Sorting Card Test (WSCT), which had the purpose of assessing their performance regarding executive function. No statistically significant difference was seen between the groups and variables tested.

The result obtained after analysis using the Test of Nonverbal Intelligence (R1) demonstrated that, from their scores, $100 \%$ of the participants from both groups had their intelligence ranked as "inferior" if compared to what was expected in view of the schooling and region studied. Table 5 shows that patients in the group LF scored lower than those in the group RF ( $\mathrm{p}=0.029)$.

Upon assessing the number of correct answers, the number of misses, the number of items left unanswered, and the overall score in the test of Concentrated Attention, no statistically significant results were obtained. Hence, there was no difference in the level of concentrated attention between the LF and RF groups (Table 6).

Table 1. Age and time since lesion onset.

\begin{tabular}{ccccccc}
\hline GROUP & & N & Minimum & Maximum & Mean & SD \\
\hline \multirow{2}{*}{ LF LESION } & Age & 6 & 14 & 76 & 54.3 & 22.2 \\
& Time sincelesion/days & 6 & 5 & 12 & 7.8 & 2.6 \\
RF LESION & Age & 10 & 16 & 89 & 56.0 & 22.2 \\
& Time sincelesion/days & 10 & 3 & 18 & 9.0 & 4.4 \\
\hline
\end{tabular}

Legend: SD—Standard deviation, LF Lesion—Left Frontal Lesion, RF Lesion—Right Frontal Lesion. 
Table 2. Sociodemographic features of the sample.

\begin{tabular}{|c|c|c|c|}
\hline GROUP & VARIABLE & $\mathrm{N}$ & $\%$ \\
\hline \multicolumn{4}{|c|}{ GENDER } \\
\hline \multirow[t]{2}{*}{ LF LESION } & Female & 3 & 50.0 \\
\hline & Male & 3 & 50.0 \\
\hline \multirow[t]{2}{*}{ RF LESION } & Female & 3 & 30.0 \\
\hline & Male & 7 & 70.0 \\
\hline \multicolumn{4}{|c|}{ SCHOOLING } \\
\hline \multirow[t]{3}{*}{ LF LESION } & Iliterate & 1 & 16.7 \\
\hline & Middleschooldropouts & 4 & 66.7 \\
\hline & High schooldropouts & 1 & 16.7 \\
\hline \multirow[t]{4}{*}{ RF LESION } & Illiterate & 2 & 20.0 \\
\hline & Finishedmiddleschool & 1 & 10.0 \\
\hline & Middleschooldropouts & 6 & 60.0 \\
\hline & High schooldropouts & 1 & 10.0 \\
\hline
\end{tabular}

Legend: LF LESION—Left Frontal Lesion, RF LESION—Right Frontal Lesion.

\section{Discussion}

This study was aimed at analyzing the topography of executive function components in patients who had suffered a cerebrovascular accident that had damaged their frontal lobe; and, according to the results obtained, there was no predominance in executive function components in the right and left frontal lobes, in other words, the executive functions are symmetrically organized in the two frontal lobes.

A study that compared the performance of healthy individuals to that of patients with a diagnosis of subcortical vascular disease and who had had a CVA highlighted the difference between the groups by showing that the greater the cerebral impairment the worse the performance in the test. Patients with vascular dementia were shown to have memory loss, diminished processing speed and verbal production, whereas patients with no vascular dementia had attention deficit [15].

The Frontal Assessment Battery (FAB) is a brief screening test consisting of 6 neuropsychological tasks aimed at evaluating frontal lobe function. The tasks involve cognitive functions and behavioral domains that are controlled by the frontal lobes. A research looked into the performance sensitivity of FAB in the frontal region of patients with injury to the right hemisphere after CVA and concluded that the integrity of the right hemisphere is crucial to a good performance in the FAB. It also demonstrated that conceptualization and mental flexibility were sensitive in the tests in patients with right middle frontal gyrus lesion [16].

Many a researcher has tried to shed light on the cognitive processes involving patients with CVA using WSCT. Among the most analyzed factors in the studies is concept formation/perseverance, which is assessed using the test. These variables were associated with dorsolateral prefrontal dysfunction and are reflected in two aspects of executive dysfunction: non-perseverative responses and problem solving, as well as the inability to shift attention in a flexible manner.

Studies have shown poor WCST performance for those patients with injuries to the subcortical areas, since these areas have robust connection to the frontal lobes, such as basal ganglia and thalamus. However, the studies do not mention any specific responsibility of the cerebral hemispheres either isolated or in conjuction [17]-[22].

Chwen-Ying Su et al. analyzed, in a pioneering way, the pattern of performance in WSCT for patients with CVA with putaminal hemorrhage, comparing the differences in WSCT performance between 55 patients with putaminal hemorrhage three months after the lesion and a control group. The results obtained by the researchers showed significant differences between the groups in five WSCT indicators (perseverative errors, perseverative responses, conceptual level responses, number of categories complete, and the number of trials to complete the first category). The patients in the study had deficits in conceptualization and perseverance when compared to the control group. Besides, they were able to complete a smaller number of categories and needed a greater 
Table 3. Clinical features of the sample.

\begin{tabular}{|c|c|c|c|}
\hline Group & VARIABLE & $\mathrm{n}$ & $\%$ \\
\hline \multicolumn{4}{|c|}{ TYPE OF CVA } \\
\hline LF LESION & Ischemic & 6 & 100.0 \\
\hline RF LESION & Ischemic & 10 & 100.0 \\
\hline \multicolumn{4}{|c|}{ SITE OF STROKE } \\
\hline \multirow[t]{3}{*}{ LF LESION } & LF & 2 & 33.3 \\
\hline & Left FPO & 1 & 16.7 \\
\hline & Left FTP & 3 & 50.0 \\
\hline \multirow[t]{5}{*}{ RF LESION } & $\mathrm{RF}$ & 4 & 40.0 \\
\hline & RFP & 2 & 20.0 \\
\hline & R Frontal & 1 & 10.0 \\
\hline & Right FTP & 2 & 20.0 \\
\hline & Right Subcortical Frontal & 1 & 10.0 \\
\hline \multicolumn{4}{|c|}{ APHASIA } \\
\hline \multirow[t]{2}{*}{ LF LESION } & No & 2 & 33.3 \\
\hline & Yes & 4 & 66.7 \\
\hline \multirow[t]{2}{*}{ RF LESION } & No & 10 & 100.0 \\
\hline & MOTOR SEQUELA & & \\
\hline \multirow[t]{4}{*}{ LF LESION } & RightHemiparesis & 3 & 50.0 \\
\hline & Right Hemiplegia & 1 & 16.7 \\
\hline & NON & 1 & 16.7 \\
\hline & RightBrachyfacialParesis & 1 & 16.7 \\
\hline \multirow[t]{2}{*}{ RF LESION } & LeftHemiparesis & 9 & 90.0 \\
\hline & Left Hemiplegia & 1 & 10.0 \\
\hline & RISK FACTORS & & \\
\hline \multirow[t]{5}{*}{ LF LESION } & SAH/Sedentarylifestyle & 2 & 33.4 \\
\hline & SAH/Diabetes/Cardiovascular disease & 1 & 16.7 \\
\hline & SAH/Diabetes/Sedentarylifestyle & 1 & 16.7 \\
\hline & SAH/Smoking/Sedentarylifestyle & 1 & 16.7 \\
\hline & Smoking/Sedentarylifestyle & 1 & 16.7 \\
\hline \multirow[t]{6}{*}{ RF LESION } & SAH/Diabetes/Sedentarylifestyle & 5 & 50.0 \\
\hline & SAH/Sedentarylifestyle & 1 & 10.0 \\
\hline & SHA/Sedentarylifestyle/Smoking & 1 & 10.0 \\
\hline & SAH/Smoking/Sedentarylifestyle & 1 & 10.0 \\
\hline & NON & 1 & 10.0 \\
\hline & Smoking & 1 & 10.0 \\
\hline & LATERALITY & & \\
\hline \multirow[t]{2}{*}{ LF LESION } & Stronglyright-handed & 5 & 83.3 \\
\hline & Moderatelyright-handed & 1 & 16.7 \\
\hline \multirow[t]{3}{*}{ RF LESION } & Stronglyright-handed & 7 & 70.0 \\
\hline & Stronglyleft-handed & 1 & 10.0 \\
\hline & Moderatelyright-handed & 2 & 20.0 \\
\hline & NUMBER OF STROKES & & \\
\hline \multirow[t]{2}{*}{ LF LESION } & 1 & 5 & 83.3 \\
\hline & 2 & 1 & 16.7 \\
\hline \multirow[t]{2}{*}{ RF LESION } & 1 & 8 & 80.0 \\
\hline & 2 & 2 & 20.0 \\
\hline
\end{tabular}

Legend: LF Lesion—Left Frontal Lesion, RF Lesion—Right Frontal Lesion, FPO—Frontal Parieto-Occipital Lesion, FTP—Frontal TemporalParietal Lesion, RFP—Right Frontal-Parietal Lesion, NON—Nothing of Note, SAH—Systemic Arterial Hypertension. 
Table 4. Comparison of the results obtained by the groups with regards to performance on the WSCT (means and SD).

\begin{tabular}{cccc}
\hline VARIABLE & RF Lesion & LF Lesion & $\mathbf{p}^{*}$ \\
\hline TRIALS ADMINISTERED & $116.8 \pm 23.3$ & $128 \pm 0.0$ & 0.274 \\
TOTAL No. ERRORS & $54.6 \pm 24.9$ & $75.4 \pm 29.9$ & 0.095 \\
\% ERRORS & $47.1 \pm 20.2$ & $58.6 \pm 23.3$ & 0.285 \\
PERSEVERATIVE RESPONSES & $11.9 \pm 11.6$ & $40.8 \pm 30.1$ & 0.052 \\
\% PERSEVERATIVE RESPONSES & $12.2 \pm 15.0$ & $31.4 \pm 23.4$ & 0.140 \\
PERSEVERATIVE ERRORS & $11.3 \pm 11.2$ & $32.8 \pm 23.3$ & 0.092 \\
\% PERSEVERATIVE ERRORS & $11.8 \pm 14.9$ & $25.4 \pm 18.2$ & 0.159 \\
NONPERSEVERATIVE ERRORS & $43.3 \pm 25.8$ & $42.6 \pm 44.7$ & 0.350 \\
\% NONPERSEVERATIVE ERRORS & $31.8 \pm 21.7$ & $33.0 \pm 34.9$ & 0.386 \\
CONCEPTUAL LEVEL RESP. & $51.4 \pm 29.1$ & $36.2 \pm 26.4$ & 0.229 \\
\% CONCEPTUAL LEVEL RESP. & $43.3 \pm 23.4$ & $27.8 \pm 20.5$ & 0.229 \\
No. CATEGORIES COMPLETED & $3.4 \pm 2.7$ & $1.6 \pm 1.8$ & 0.194 \\
TRIALS TO COMPLETE FIRST CATEGORY & $17.1 \pm 18.7$ & $29.2 \pm 41.2$ & 0.837 \\
FAILURE TO MAINTAIN SET & $1.3 \pm 0.7$ & $1.6 \pm 1.5$ & 1.000 \\
LEARNING TO LEARN & $-4.0 \pm 5.0$ & $-10.0 \pm 9.9$ & 0.688 \\
\hline
\end{tabular}

Legend: WSCT—Wisconsin Sorting Card Test, SD—Standard Deviation, RF Lesion—Right Frontal Lesion, LF Lesion—Left Frontal Lesion. Comparison between the groups was made using the Man-Whitney test.

Table 5. Scoring on the test of nonverbal intelligence-R1.

\begin{tabular}{cccccc}
\hline & RF LESION & LF LESION & & \\
\hline VARIABLE & MEAN & SD & MEAN & SD & $\mathbf{p}^{*}$ \\
\hline SCORE R1 & 8.4 & 3.7 & 4.3 & 1.5 & 0.029 \\
\hline
\end{tabular}

Legend: SD—Standard Deviation, RF Lesion—Right Frontal Lesion, LF Lesion—Left Frontal Lesion. Comparison between the groups was made using the Man-Whitney test.

Table 6. Test of concentrated attention (means, SD, p score).

\begin{tabular}{cccccc}
\hline & RF LESION & \multicolumn{2}{c}{ LF LESION } & & \\
\hline VARIABLE & MEAN & SD & MEAN & SD & $\mathbf{p}^{*}$ \\
CORRECT CA & 14.0 & 22.0 & 9.0 & 1.0 & 0.515 \\
MISSES CA & 9.4 & 7.4 & 5.0 & 2.6 & 0.337 \\
UNANSWERED CA & 40.8 & 40.0 & 87.0 & 71.9 & 0.518 \\
OVERALL CA & -32.8 & 52.3 & -83.0 & 70.3 & 0.354 \\
\hline
\end{tabular}

Legend: CA—Concentrated Attention, SD—Standard Deviation, RF Lesion—Right Frontal Lesion, LF Lesion—Left Frontal Lesion. Comparison between the groups was made using the Man-Whitney test.

number of trials to complete the first category. They then concluded that there is no significant effect of hemispheric lateralization for any of the WSCT variables [23]. The results of this research are in accordance with those reached by other authors [24]-[27].

Eslinger PJ and Grattan LM noticed that patients with unilateral vascular lesions of the caudate nucleus, putamen, and the anterior limb of the internal capsule showed increased perseveration on the WSCT [27].

It is known that the WSCT is one of the most frequently administered neuropsychological tests and that some of the most common executive function impairments are the result of ischemic CVAs. Jodzio K and Biechowska Dum carried out a research meant to evaluate the diagnostic use of the WCST as a measure of the executive dysfunction in post-stroke patients. The researchers assessed 44 patients who had recently had unilateral CVA (22 in the left hemisphere and 22 in the right hemisphere) by means of the WSCT. The results demonstrated a 
negative predictive value greater than the positive predictive value, in other words, normal scoring in the WSCT reliably point to the absence of executive dysfunctions. Performance on the WCST was clearly influenced by the severity of the executive dysfunctions, that is, those patients who presented with severe impairment of their executive functions (measured by go/no-go, fluency, and other tests that appraise executive functions) had a worse performance on the WCST. Lastly, an assessment using multivariate analysis of variance, looking at anterior versus posterior lesions and to the right and left of the lesion as independent variables, revealed a relatively feeble effect of the location of the lesion upon the result on the WCST. Only in the analysis done with the variable "number of completed categories" did we see a smaller number of categories completed in patients with left rather than right hemisphere brain damage [28]. The data from the study by Jodzio K and Biechowska Dum do confirm those found in our study as to the number of categories completed on the WCST being lower for the group of patients with left hemisphere brain damage.

A study was conducted in which divided and concentrated attention were evaluated for post-stroke individuals using the Comprehensive Assessment Battery of Mental Functions 1 and 2 (BGFM-1; BGFM-2); the first was aimed at assessing divided attention, the second at measuring concentrated attention. By not showing any significant difference between the groups that were studied, the statistical analysis did corroborate this research [29].

Eight patients suffering from aphasia were selected immediately after ictus with the objective of appraising their intelligence using nonverbal tests. The study shows that intelligence measured by the Leiter nonverbal test is better preserved in some aphasic patients [30].

When appraising the intelligence of the patients in our study, in spite of their having been tallied as "inferior" in the R1 test, those in the LF scored lower on the test $(\mathrm{p}=0.029)$, probably because the right hemisphere is the one responsible for functions such as attention, perception and visual/spatial memory, right-left awareness, social and emotional intelligence, recognition of facial expressions and musical ability, that is, nonverbal skills that are compatible with the sort of test employed. No difference was observed between the groups in this study with regard to the level of concentrated attention in patients with damage to the left or right frontal lobe.

\section{Conclusion}

The conclusion reached in this study is that executive functions are symmetrically organized in the two frontal lobes, since the comparison between the groups did not demonstrate a statistically significant difference for any of the variables of WSCT.

\section{Competing Interests}

The authors report no conflicts of interest.

\section{References}

[1] Hamdan, A. and Pereira, A.P. (2009) Neuropsychological Assessment of Executive Functions: Methodological Questions. Psicologia: Reflexão e Crítica, 22, 386-393. http://dx.doi.org/10.1590/S0102-79722009000300009

[2] Jodzio, K. (2008) Neuropsychologu of Intentional Action. Concepts of Executive Functions. Wydawnictwo Naukowe SCHOLAR, Warsal.

[3] World Health Organization (2002) World Health Report 2002. Reducing Risks, Promoting Healthy Life. Geneva. http://www.who.int/whr/2002/en/

[4] Abe, I.L., Lotufo, P.A., Goulart, A.C. and Benseñor, I.M. (2011) Stroke Prevalence in a Poor Neighbourhood of São Paulo, Brazil: Applying a Stroke Symptom Questionnaire. International Journal of Stroke, 6, 33-39. http://dx.doi.org/10.1111/j.1747-4949.2010.00538.x

[5] Snaphaan, L. and de Leeuw, F.E. (2007) Poststroke Memory Function in Nondemented Patients: A Systematic Review on Frequency and Neuroimaging Correlates. Stroke, 38, 198-203. http://dx.doi.org/10.1161/01.STR.0000251842.34322.8f

[6] Melkas, S., Jokinen, H., Hietanen, M. and Erkinjuntti, T. (2014) Poststroke Cognitive Impairment and Dementia: Prevalence, Diagnosis, and Treatment. Degenerative Neurological and Neuromuscular Disease, 4, 21-27. http://dx.doi.org/10.2147/DNND.S37353

[7] Gouveia, P.A.R. and Prade, C.V. (2008) Intervenção neuropsicológica do paciente vítima de acidente vascular cerebral. In: Knobel, E., Atheneu, Rio de Janeiro.

[8] Brookshire, R.H. (2003) Introduction to Neurogenic Communication Disorders. Mosby, Missouri. 
[9] Marchetti, C., Carey, D. and Della Sala, S. (2005) Crossed Right Hemisphere Syndrome Following Left Thalamic Stroke. Journal of Neurology, 252, 403-411. http://dx.doi.org/10.1007/s00415-005-0656-8

[10] Myers, P.S. (2001) Toward a Definition of RHD Syndrome. Aphasiology, 15, 913-918. http://dx.doi.org/10.1080/02687040143000285

[11] Malloy-Diniz, L.F., Fuentes, D., Mattos, P. and e Abreu, N. (2010) Avaliação neuropsicológica. Artmed, Porto Alegre.

[12] Fuster, J.M. (2008) The Prefrontal Córtex. 4th Edition, Academic Press, London.

[13] Huber, S.J., Bornstein, R.A., Rammohan, K.W., Christy, J.A., Chakeres, D.W. and McGhee, R.B. (1992) Magnetic Resonance Imaging Correlates of Executive Functions Impairments in Multiple Sclerosis. Neuropsychiatry and Clinical Neuroscience, 4, 152-158. http://dx.doi.org/10.1176/jnp.4.2.152

[14] Nelson, H.E. (1976) A Modified Card Sorting Test Sensitive to Frontal Lobe Defects. Cortex, 12, 313-324. http://dx.doi.org/10.1016/S0010-9452(76)80035-4

[15] De Andrade, S.P.C., Brucki, S.M.D., Bueno, O.F.A. and Neto, J.I.S. (2012) Neuropsychological Performance in Patients with Subcortical Stroke. Arquivos de Neuro-Psiquiatria, 70, 341-347. http://dx.doi.org/10.1590/S0004-282X2012005000012

[16] Kopp, B., Rösser, N., Tabeling, S., Stürenburg, H.J., de Haan, B., Karnath, H. and Wessel, K. (2013) Performance on the Frontal Assessment Battery Is Sensitive to Frontal Lobe Damage in Stroke Patients. BMC Neurology, 13, 179. http://dx.doi.org/10.1186/1471-2377-13-179

[17] Taylor, A.E., Saint-Cyr, J.A. and Lang, A.E. (1986) Frontal Lobe Dysfunction in Parkinson's Disease. The Cortical Focus of Neostriatal Outflow. Brain, 109, 845-883. http://dx.doi.org/10.1093/brain/109.5.845

[18] Weinberger, D.R., Berman, K.F., Iadarola, M., Driesen, N. and Zec, R.F. (1988) Prefrontal Cortical Blood Flow and Cognitive Function in Huntington's Disease. Journal of Neurology Neurosurgery Psychiatry, 51, 94-104. http://dx.doi.org/10.1136/jnnp.51.1.94

[19] Troyer, A.K., Black, S.E., Armilio, M.L. and Moscovitch, M. (2004) Cognitive and Motor Functioning in a Patient with Selective Infarction of the Left Basal Ganglia: Evidence for Decreased Non-Routine Response Selection and Performance. Neuropsychologia, 42, 902-911. http://dx.doi.org/10.1016/j.neuropsychologia.2003.12.003

[20] Ances, B. and Chatterjee, A. (2003) Shopping List Perseveration. Neurology, 60, 1975. http://dx.doi.org/10.1212/01.WNL.0000064171.95314.88

[21] Pickett, E.R., Kuniholm, E., Protopapas, A., Friedman, J. and Lieberman, P. (1998) Selective Speech Motor, Syntax and Cognitive Deficits Associated with Bilateral Damage to the Putamen and the Head of the Caudate Nucleus: A Case Study. Neuropsychologia, 36, 173-188. http://dx.doi.org/10.1016/S0028-3932(97)00065-1

[22] Karussis, D., Leker, R.R. and Abramsky, O. (2000) Cognitive Dysfunction Following Thalamic Stroke: A Study of 16 Cases and Review of the Literature. Journal of the Neurological Sciences, 172, 25-29. http://dx.doi.org/10.1016/S0022-510X(99)00267-1

[23] Su, C.Y., Wuang, Y.P., Chang, J.K., Guo, N.W. and Kwan, A.L. (2006) Wisconsin Card Sorting Test Performance after Putaminal Hemorrhagic Stroke. Kaohsiung Journal of Medical Sciences, 22, 75-84. http://dx.doi.org/10.1016/S1607-551X(09)70224-4

[24] Monchi, O., Petrides, M., Petre, V., Worsley, K. and Dagher, A. (2001) Wisconsin Card Sorting Revisited: Distinct neural Circuits Participating in Different Stages of the Task Identified by Event-Related Functional Magnetic Resonance Imaging. The Journal of Neuroscience, 21, 7733-7741.

[25] Tiihonen, J., Vilkman, H., Rasanen, P., Ryynänen, O.P., Hakko, H., Bergman, J., Hämäläinen, T., Laakso, A., Haaparanta-Solin, M., Solin, O., Kuoppamäki, M., Syvälahti, E. and Hietala, J. (1998) Striatal Presynaptic Dopamine Function in Type 1 Alcoholics Measured with Positron Emission Tomography. Molecular Psychiatry, 3, $156-161$. http://dx.doi.org/10.1038/sj.mp.4000365

[26] Monchi, O., Taylor, J.G. and Dagher, A. (2000) A Neural Model of Working Memory Processes in Normal Subjects, Parkinson's Disease and Schizophrenia for fMRI Design and Predictions. Neural Networks, 13, 953-973. http://dx.doi.org/10.1016/S0893-6080(00)00058-7

[27] Eslinger, P.J. and Grattan, L.M. (1993) Frontal Lobe and Frontal-Striatal Substrates for Different Forms of Human Cognitive Flexibility. Neuropsychologia, 31, 17-28. http://dx.doi.org/10.1016/0028-3932(93)90077-D

[28] Jodzio, K. and Biechowska, D. (2010) Wisconsin Card Sorting Test as a Measure of Executive Function Impairments in Stroke Patients. Applied Neuropsychology, 17, 267-277. http://dx.doi.org/10.1080/09084282.2010.525104

[29] Lima, E.S.H., de Medeiros, P.C.B. and Feitosa, L.C. (2014) Avaliação da atenção dividida e concentrada em pacientes pós acidente vascular encefálico. http://www.simed.estatistico.com/trabalhos/poster/SIMED_Poster009.pdf

[30] Ceschin, J.S., Brauer, M.J., Filho, R.M. and Parente, M.A.M.P. (1979) Avaliação da inteligência com testes não-verbais em afásicos. Arquivos de Neuro-Psiquiatria, 37, 284-289. http://dx.doi.org/10.1590/S0004-282X1979000300007 